\title{
PENGARUH MODEL PEMBELAJARAN PROBLEM BASED LEARNING (PBL) TERHADAP KEMAMPUAN BERPIKIR KRITIS MATEMATIS SISWA PADA MATERI SISTEM PERSAMAAN LINEAR DUA VARIABEL
}

\section{THE EFFECT OF MODEL PROBLEM BASED LEARNING (PBL) ON STUDENT'S MATHEMATICAL CRITICAL THINKING SKILLS TO THE MATTER ON TWO VARIABLE LINEAR EQUATION SYSTEMS}

\author{
HAYATUN NUFUS ${ }^{1}$, HERIZAL ${ }^{2}$, LINDA DEWI SAHPUTRI ${ }^{3}$ \\ ${ }^{123}$ Program Studi Pendidikan Matematika, Universitas Malikussaleh, Aceh Utara, Indonesia \\ Jl. Cot Teuku Nie Reuleut Kecamatan MuaraBatu-Aceh Utara, \\ 1email:hayatun.nufus@unimal.ac.id \\ ²email:herizal_mathedu@unimal.ac.id \\ ${ }^{3}$ email:lindadewii1212@gmail.com
}

\begin{abstract}
Abstrak
Matematika merupakan pelajaran wajib yang sudah diajarkan semenjak dasar hingga menengah, matematika dapat melatih dan mengembangkan kemampuan berpikir siswa. Namun, banyak siswa yang menganggap matematika adalah mata pelajaran yang sulit dipahami. Siswa cenderung menghindari bahkan takut untuk belajar matematika, sehingga menyebabkan rendahnya kemampuan berpikir kritis matematis siswa. Penelitian ini bertujuan untuk mengetahui pengaruh model pembelajaran Problem Based Learning (PBL) terhadap kemampuan berpikir kritis matematis siswa. Penelitian ini menggunakan pendekatan kuantitatif dengan jenis penelitian Quasi Eksperimental Design dan rancangan penelitianThe Non equivalent Postets-Only Control Grup Design.Populasidalampenelitian ini adalah kelas VIII SMP Negeri 4 Dewantara, sementara sampelnya yaitu kelas $\mathrm{VIII}_{2}$ dan $\mathrm{VIII}_{3}$ dengan teknik pengambilan sampel adalah Purposive Sampling. Adapun Teknik pengumpulandatayangdigunakandalam penelitianini adalah tes kemampuanberpikirkritis matematis siswa. Analisis data yang dilakukan untuk tes kemampuan berpikir kritis matematis menggunakan uji-t karena data berdistribusi normal dan homogen. Dari hasil uji hipotesis didapatkan nilai signifikan 0,001 yang artinya tolak $\mathrm{H}_{0}$ sehingga dapat disimpulkan bahwa dengan menggunakan model pembelajaran Problem Based Learning (PBL) berpengaruh pada kemampuan berpikir kritis matematissiswa.
\end{abstract}

Kata Kunci : Kemampuan Berpikir Kritis Matematis, Problem Based Learning.

\begin{abstract}
Abstrak
Mathematics is a compulsory subject that has been taught from elementary to middle school, mathematics can train and develop students' thinking skills. However, many students consider mathematics to be a difficult subject to understand. Students tend to avoid and even fear learning mathematics, resulting in low students' mathematical critical thinking skills. This study aims to determine the effect of the Problem Based Learning (PBL) learning model on student's mathematical critical thinking skills. This research uses a quantitative approach with the type of research Quasi Experimental Design and the research design of The Nonequivalent Postets-Only Control Group Design. The population in this study was class VIII SMP Negeri 4 Dewantara, while the sample was class $\mathrm{VIII}^{2}$ and $\mathrm{VIII}^{3}$ with the sampling technique using purposive sampling. The data collection technique used in this study was a test of students' mathematical critical thinking skills. The data analysis conducted for the test of mathematical critical thinking skills used the t-test because the data were normally distributed and homogeneous. From the results of the hypothesis test, it was obtained a significant value of 0.001 , which means reject $\mathrm{H}_{\mathrm{o}}$, so it can be concluded that using the Problem Based Learning (PBL) learning model has an effect on students' mathematical critical thinking skills.
\end{abstract}

Keywords : Mathematical Critical Thinking, Problem Based Learning. 
Hal : $12-19$

\section{Pendahuluan}

Perkembangan di era globalisasi menuntut sumber daya manusia yang berpendidikan serta berkualitas untuk mencapai kemajuan diberbagai bidang. Pendidikan merupakan salah satu yang berperan penting untuk mengembangkan sumber daya manusia yang berkualitas. Pendidikan harus berkualitas, agar melahirkan dan menciptakan sumber daya manusia yang cerdas serta berkembang. Meningkatkan kualitas pendidikan sangat penting sehingga pemerintah harus lebih serius dalam bidang pendidikan, sebab dengan sistem pendidikan yang baik diharapkan muncul generasi penerus bangsa yang berpendidikkan dan berkualitas. Hal yang perlu diperhatikan dalam upaya peningkatan kualitas pendidikan adalah proses penyelenggaraan pembelajaran, dimana dalam proses pembelajaran komponen yang terlibat adalah guru dan siswa. Guru sebagai pendidik memegang peran yang penting dalam keberhasilanproses pembelajaran dari siswa.Guru mengajarkan beberapa matapelajaran di sekolah seperti dalam Undang-undang nomor 20 tahun 2003 tentang Sistem Pendidikan Nasional pasal 37 ayat 1 menyatakan kurikulum pendidikan dasar dan menegah wajib memuat: pendidikan agama, pendidikan kewarganegaraan, bahasa Indonesia, matematika, ilmu pengetahuan alam, ilmu pengetahuan sosial, seni dan budaya, pendidikan jasmani dan olahraga, keterampilan, dan muatan lokal[1].

Matematika merupakan mata pelajaran wajib di sekolah yang diajarkan sejak sekolah dasar sampai sekolah menegah. Matematika adalah salah satu matapelajaran yang ikut serta dalam mencerdaskan generasi bangsa agar mampu bersaing di era globalisasi yangsemakin maju. Mempelajari matematika tidak merugikan karena dalam kehidupan sehari-hari matematika sangat sering kita temukan baik sadar ataupun tidak sadar. Matematika juga membantu siswa melatih, menggunakan dan mengembangkan kemampuan berpikirnya[2]. Pengembangan keterampilan berpikir kritis dalam pembelajaran matematika sangat mungkin, karena materi matematika dan keterampilan berpikir kritis merupakan dua hal yang tidak bisa dipisahkan. Materi matematika dipahami melalui berfikir kritis, danberfikir kritis dilatih melalui pembelajaran matematika[3].

Akan tetapi, tidak heran lagi jika matematika menjadi mata pelajaran yang masih dianggap sulit dipahami para siswa. Siswa cenderung menghindar bahkan takut untuk belajar matematika, sehingga dapat mengurangi prestasi siswa dalam belajar. Hasil wawancara dan observasi dengan guru matematika kelas VIII disekolah SMP Negeri 4 Dewantara yaitu Ibu Iqramina diperoleh bahwa kemampuan berpikir kritis matematis siswa masih tergolong rendah, karena siswa kurang minat dalam pembelajaran, kurang merespon terhadap pembelajaran matematika serta hanya menerima materi yang diajarkan guru tanpa mempelajari atau memikirkan ulang apa yang telah disampaikan. Siswa cenderung fokus pada penjelasan guru saja tanpa ada inisiatif bertanya, jadi saat guru memberikan soal siswa menjawab soal tersebut tanpa memahami cara penyelesaiannya. Permasalahan tersebut menjadi penyebab terhambatnya kemampuan berpikir kritis matematis siswa sehingga menurunkan prestasi belajar siswa.

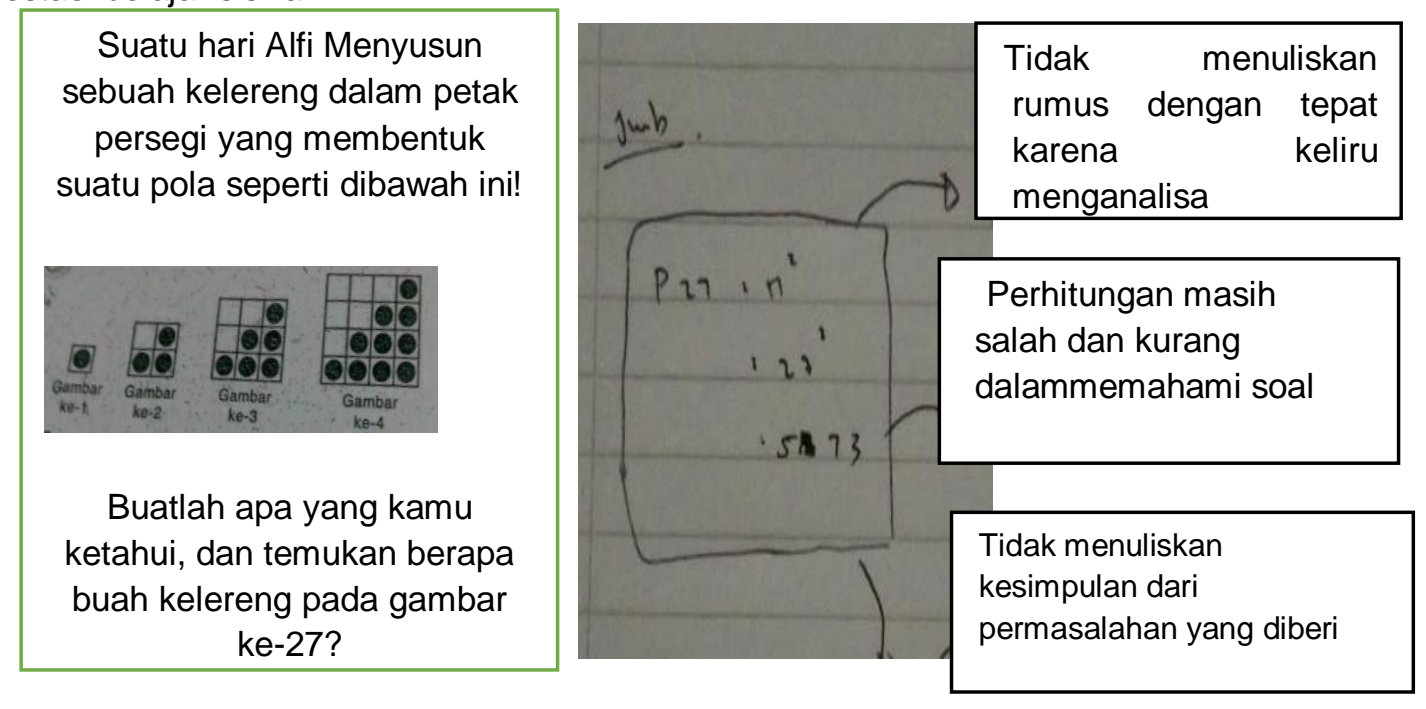

Gambar 1. Hasil tes jawaban siswa 
Berdasarkan hasil tes awal pada salah satu kelas VIII di SMP Negeri 4 Dewantara tentang materi Pola Bilangan yang terlihat dari gambar di atas, solusi yang diberikan siswa pada jawaban tersebut jauh dari yang diharapkan. Penggunaan rumus yang kurang tepat dalam menjawab soal, serta siswa kurang teliti dan tidak menuliskan apa yang diketahui dan ditanyakan dalam soal tersebut, dalam memecahkan masalah dari soal tersebut siswa masih kurang mampu memahami apa yang menjadi permasalahan dari soal tersebut. Hal ini menunjukkan bahwa daya pikir siswa masih terbilang rendah dan belum mampu menganalisa suatu permasalahan.

Berdasarkan permasalahan yang terjadi di SMP Negeri 4 Dewantara maka perlu diterapkan suatu sistem pembelajaran yang dapat membantu siswa meningkatkan kemampuan berpikir kritis dalam proses pembelajaran, guna meningkatkan prestasi belajar matematika disetiap jenjang pendidikan. Salah satu model pembelajaran yang mampu membantu siswa dalam meningkatkan kemampuan berfikir kritis adalah model pembelajaran Problem Based Learning(PBL). Problem Based Learning (PBL) memberikan sebuah masalah yang dikemukakan kepada siswa yang dapat membangkitkan pemahaman siswa terhadap masalah, sebuah kesadaran akan adanya kesenjangan, pengetahuan, keinginan memecahkan masalah, dan adanya persepsi bahwa mereka mampu memecahkan masalah tersebut[4].

Problem Based Learning (PBL) sangat cocok diterapkan dalam matematika karena dalam mempelajari matematika tidak cukup hanya mengetahui konsep-konsep saja, tetapi dibutuhkan pemahaman dan kemampuan dalam menyelesaikan persoalan matematika. Hal ini sejalan dengan hasil penelitian Rochmah (2016) dan juga penelitian Sianturi, dkk (2018) yang mengatakan pembelajaran Problem Based Learning (PBL) sangat berpengaruh terhadap kemampuan berpikir kritis matematis siswa dalam menyelesaikanmasalah[5][6]. Berdasarkan pemikiran di atas, maka peneliti tertarik untuk melakukan suatu penelitian yang berjudul: "Pengaruh Model Pembelajaran Problem Based Learning (Pbl) Terhadap Kemampuan Berpikir Kritis Matematis SiswaPada Materi Sistem Persamaan Linear Dua variabel di Kelas VIII SMP Negeri 4 Dewantara".

\section{Metode Penelitian}

Penelitian ini menggunakan penelitian kuantitatif, dan menggunakan metode Quasi eksperimen, dimana akan menerapkan pembelajaranmodel Problem Based Learning (PBL) dalam proses pembelajaran untuk kelas eksperimen dan pembelajaran konvensional untuk kelas kontrol sebagaipembanding.Dalampenelitianini kelas tidak pilih secara random, jadi desain rancangan penelitian ini adalah The Nonequivalent Postets-Only Control Grup Design [7]). Maka rancangan pada penelitian iniadalah:

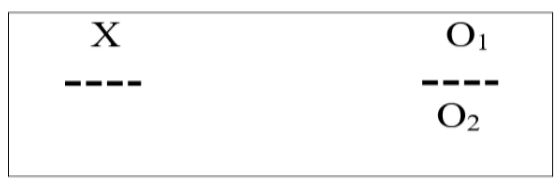

Gambar 1. Rancangan Penelitian

Keterangan:

X : Model Pembelajaran Problem Based Learning (PBL)

O1 : Post-test untuk kelasEksperimen

O2 : Post-test untuk kelas kontrol

Penelitian ini dilaksanakan di kelas VIII SMP Negeri 4 Dewantara pada semester genap tahun pelajaran 2020/2021. Adapun yang menjadi populasi dalam penelitian ini adalah seluruh siswa kelas VIII SMP Negeri 4 Dewantara tahun ajaran 2020/2021. Sedangkan sampel yang terpilih dalam penelitian ini dengan teknik Purposive Sampling adalah VIII3 sebagai kelas eksperimen yaitu kelas yang menggunakan model pembelajaran Problem Based Learning (PBL) dan kelas VIII2 sebagai kelas kontrol yaitu sebagai kelas pembanding yang tidak menggunakan model pembelajaran Problem Based Learning (PBL). Penelitian ini menggunakanjenis instrumennya adalah tes kemampuan berpikir kritis dan lembar observasi aktivitas guru dan siswa. Teknik pengumpulan data yang dikumpulkan oleh penelitian adalah data dari hasil post-test. Sebelum digunakan soal tes akan diuji validitas, reliabilitas, daya pembeda dan 
Hal : $12-19$

tingkat kesukaran soal tersebut. Berikut ini hasil validasi instrument tes yang diuji sebanyak 7 butir soal.

Tabel 1. Nilai Validitas Soal

\begin{tabular}{|c|l|l|l|l|}
\hline Nomor Soal & Rxy & thitung & ttabel & Interpretasi \\
\hline 1 & 0,74 & 4,13 & 1,76 & Valid \\
\hline 2 & 0,70 & 3,72 & 1,76 & Valid \\
\hline 3 & 0,64 & 3,14 & 1,76 & Valid \\
\hline 4 & 0,76 & 4,49 & 1,76 & Valid \\
\hline 5 & 0,21 & 0,82 & 1,76 & Tidak Valid \\
\hline 6 & 0,33 & 1,34 & 1,76 & Tidak Valid \\
\hline 7 & 0,76 & 4,42 & 1,76 & Valid \\
\hline
\end{tabular}

Tabel 2. Nilai Reliabilitas Soal

\begin{tabular}{|c|c|c|}
\hline Tes & $\begin{array}{c}\text { Kofisien } \\
\text { Reliabilitas }\end{array}$ & Interpretasi \\
\hline $\begin{array}{c}\text { Kemampuan } \\
\text { Berpikir Kritis }\end{array}$ & 0,71 & Tinggi \\
\hline
\end{tabular}

Tabel 3. Nilai Daya Pembeda Soal

\begin{tabular}{|c|c|c|}
\hline Butir Soal & Daya Pembeda & Interpretasi \\
\hline 1 & 0,43 & Baik \\
\hline 2 & 0,5 & Baik \\
\hline 3 & 0,42 & Baik \\
\hline 4 & 0,39 & Cukup \\
\hline 5 & $-0,03$ & Kurang \\
\hline 6 & 0,14 & Kurang \\
\hline 7 & 0,46 & Baik \\
\hline
\end{tabular}

Tabel 4. Nilai Tingkat Kesukaran Soal

\begin{tabular}{|c|c|c|}
\hline No. Soal & Tingkat Kesukaran & Interpretasi \\
\hline 1 & 0,53 & Sedang \\
\hline 2 & 0,5 & Sedang \\
\hline 3 & 0,28 & Sukar \\
\hline 4 & 0,42 & Sedang \\
\hline 5 & 0,76 & Mudah \\
\hline 6 & 0,53 & Sedang \\
\hline 7 & 0,51 & Sedang \\
\hline
\end{tabular}

Tabel 5. Rangkuman Hasil Tes Kemampuan Berpikir Kritis

\begin{tabular}{|c|c|c|c|c|c|}
\hline $\begin{array}{l}\text { Butir } \\
\text { Soal }\end{array}$ & Validitas & Reliabilitas & $\begin{array}{c}\text { Daya } \\
\text { Pembeda }\end{array}$ & $\begin{array}{c}\text { Tingkat } \\
\text { Kesukaran }\end{array}$ & Keterangan \\
\hline 1 & Valid & \multirow{7}{*}{ Tinggi } & Baik & Sedang & Digunakan \\
\hline 2 & Vali & & Baik & Sedang & Digunakan \\
\hline 3 & Valid & & Baik & Sukar & Digunakan \\
\hline 4 & Valid & & Cukup & Sedang & Digunakan \\
\hline 5 & Tidak Valid & & Kurang & Mudah & Tidak digunakan \\
\hline 6 & Tidak Valid & & Kurang & Sedang & Tidak Digunakan \\
\hline 7 & Valid & & Baik & Sedang & Digunakan \\
\hline
\end{tabular}


Hal : $12-19$

Kesimpulan yang diperoleh yaitu dari 7 soal uji instrument yang telah dilakukan uji validitas, reliabilitas, daya pembeda, dan tingkat kesukaran, maka diperoleh 5 soal yang digunakan sebagai soal post-tes, adapun soal tersebut yaitu nomor 1, 2, 3, 4, dan 7 .

Teknik analisis data yang digunakan dalam penelitian ini yaitu menggunakan uji normalitas, uji homogenitas dan uji hipotesis. Uji normalitas dilakukan untuk melihat bahwa data yang diperoleh memiliki sebaran secara normal atau tidak dengan bantuan Software IBM SPSS 18. Setelah data berdsitribusi normal dilakukan uji homogenitas yang bertujuan untuk membuktikan data dasar yang akan diolah adalah homogen, setelah mengetahui data tersebut berdistirbusi normal dan memiliki varians homogeny maka selanjutnya dilakukan uji hipotesis atau uji-t dengan berbantuan Software IBM SPSS 18. Pengujian ini bertujuan untuk mengetahui apakah terdapat pengaruh model pembelajaran Problem Based Learning (PBL) terhadap kemampuan berpikir kritis matematis Siswa Pada Materi Sistem Persamaan Linear Dua Variabel di kelas VIII SMP Negeri 4 Dewantara.

\section{Hasil dan Pembahasan}

Pengolahan data dilakukan sesuai dengan ketentuan pada BAB III, data yang telah dikumpulkan dan diperoleh oleh peneliti merupakan data hasil intrumen tes berupa Post-test kemampuan berpikir matematis siswa yang dilakukan pada saat akhir pembelajaran yang dilakukan. Data hasil penelitian yang telah dilakukan meliputi data hasil belajar siswa baik di kelas eksperimen dengan jumlah siswa 18 orang menggunakan model pembelajaran Problem Based Learning (PBL) dan juga kelas kontrol dengan jumlah siswa 18 orang menggunakan model konvensional. Pengolahan data hasil tes kemampuan berpikir kritis matematisis siswa menggunakan IBM SPSS versi 18, berikut merupakan tabel yang menggambarkan data statistik deskriptif Post-test untuk tes kemampuan berpikir kritis matematis siswa

Tabel 1. Statistik Deskriptif

\begin{tabular}{|c|c|c|c|c|c|}
\hline & $\mathrm{N}$ & Minimum & Maksimum & Mean & Std. Deviation \\
\hline Eksperimen & 18 & 12 & 20 & 15.83 & 1.927 \\
\hline Kontrol & 18 & 8 & 20 & 12.94 & 2.879 \\
\hline
\end{tabular}

Tabel tersebut menunjukkan bahwa skor minimum Post-test di kelas eksperimen adalah12 dan dikelas kontrol skor minimumnya 8, sedangkan untuk skor maksimal dikedua kelas sama yaitu 20. Dapat kita lihat nilai rata-rata kemampuan berpikir kritis matematis siswa di kelas eksperimen 15.83 lebih tinggi dibandingkan rata-rata kemampuan berpikir kritis matematis siswa di kelas kontrol 12.94. Berikut ini uraian hasil pengujian normalitas, homogenitas dan uji hipotesis data skor kemampuan berpikir kritis matematis siswa yang diolah menggunakan IBM SPSS18.

Tabel 2. Hasil Uji Normalitas

\begin{tabular}{|c|c|c|c|}
\hline \multirow{2}{*}{ Kelas } & \multicolumn{3}{|c|}{ Shapiro-Wilk } \\
\cline { 2 - 4 } & Statistik & Df & Sig \\
\hline Eksperimen & 0.957 & 18 & 0.546 \\
\hline Kontrol & 0.959 & 18 & 0.580 \\
\hline
\end{tabular}

Berdasarkan hasil uji normalitas di tabel tersebut, nilai signifikan kelas eksperimen 0,546 sedangkan kelas kontrol 0,580. Berdasarkan ketentuan hipotesis uji normalitas terima $\mathrm{H} 0$ jika signifkan > 0,05. Sehingga dapat disimpulkan bahwa skor post-test kemampuan berpikir kritis matematis siswa berdistribusi normal. Setelah mengetahui bahwa data berdsitribusi normal dapat dilanjutkan dengan uji homogenitas.

Tabel 3. Hasil Uji Homogenitas 


\begin{tabular}{|c|c|c|c|}
\hline Levene Statistic & $\mathrm{df} 1$ & $\mathrm{df} 2$ & Sig \\
\hline 2.118 & 1 & 34 & 0.155 \\
\hline
\end{tabular}

Dari tabel tersebut dapat dilihat bahwa nilai signifikan uji homogenitas yaitu sebesar 0,155 . Sesuai dengan kriteria hipotesis uji homogenitas terima $\mathrm{Ho}$ jika signifkan $>0.05$, maka data hasil tes kemampuan berpikir kritis matematis siswa tersebut homogen. Karena asumsi normalitas dan homogenitas terpenuhi maka selanjutnya dilakukan pengujian hipotesis.

Tabel 4.4 Hasil Uji Hipotesis
\begin{tabular}{|c|c|c|c|}
\hline Statistic & T & Df & Sig \\
\hline Equal Variances Assumed & 3.543 & 34 & 0.001 \\
\hline
\end{tabular}

Dari tabel tersebut dapat dilihat bahwa nilai signifikan yang diperoleh adalah 0,001 . Sesuai kriteria uji hipotesis maka hasil uji hipotesis pada penelitian ini adalah tolak $\mathrm{Ho}$ dan alternatif maka terima $\mathrm{Ha}$, yaitu terdapat pengaruh model pembelajaran Problem Based Learning (PBL) terhadap kemampuan berpikir kritis matematis siswa pada materi Sistem Persamaan Linear Dua variabel kelas VIII SMP Negeri 4 Dewantara.

\section{Pembahasan}

Penelitian ini dilaksanakan untuk mengetahui pengaruh model pembelajaran Problem Based Learning (PBL) terhadap kemampuan berpikir kritis matematis siswa. Penelitian dilaksanakan pada semester genap tahun ajaran 2020/2021 pada tanggal 06 sampai 20 Januari 2021 di kelas VIII2 dan VIII3 SMP Negeri 4 Dewantara, dimana VIII3 sebagai kelas eksperimen dengan perlakuan diberi model pembelajaran Problem Based Learning (PBL) dan kelas VIII2 sebagai kelas kontrol dengan menggunakan pembelajaran konvensional dan materi yang diajarkan adalah materi sistem persamaan linear dua variabel. Data yang didapatkan peneliti diolah dengan berbantuan Software IBM SPSS18.

Hasil analisis data uji kemampuan berpikir kritis matematis yang diperoleh menunjukkan nilai ratarata kelas eksperimen 15,83 lebih tinggi dari pada nilai rata-rata kelas kontrol 12,94. Selanjutnya dilakukan uji normalitas yang mana diperoleh hasil signifikan untuk kelas eksperimen 0,546 $>0,05$ dan untuk kelas kontrol bersignifikan 0,580 >0,05 sehingga $\mathrm{HO}$ diterima, maka dapat disimpulkan data tersebut berdistribusi normal. Karena data yang diperoleh berdistribusi normal maka bisa kita lanjutkan dengan uji homogenitas. Hasil signifikan yang diperoleh yaitu 0,155 > 0,05 sehingga $\mathrm{HO}$ diterima maka data tersebut berdistirbusi homogen. Setelah peneliti memperoleh bahwa data tersebut berdistribusi normal dan juga berdistribusi homogen maka langkah selanjutnya uji hipotesis, yang mana diperoleh signifikan $0,001<\alpha=0,05$ sehingga $\mathrm{HO}$ tolak sementara $\mathrm{Ha}$ diterima dan dapat disimpulkan bahwaa penelitian yang telah dilakukan berhasil karena terdapat pengaruh.

Berdasarkan hasil uji hipotesis yang sudah dilakukan peneliti, hasilnya menunjukkan bahwa terdapat pengaruh model pembelajaran Problem Based Learning (PBL) terhadap kemampuan berpikir kritis matematis siswa pada materi sistem persamaan linear dua variabel di kelas VIII. Hal ini sejalan dengan penelitian Rochmah (2016) dan Sianturi, Sipayung dan Simorangkir (2018) yang menyatakan bahwa hasil analisis data menunjukkan bahwa pembelajaran Problem Based Learning (PBL) berpengaruh terhadap kemampuan berpikir kritis matematis siswa.

\section{Kesimpulan}

Berdasarkan hasil penelitian yang dilaksanakan mengenai pembelajaran dengan menggunakan model pembelajaran Problem Based Learning (PBL), peneliti memperoleh bahwa data hasil uji hipotesis atau uji-t diperoleh signifikan 0,001 $<\alpha=0,05$ sehingga $\mathrm{H} 0$ ditolak sementara $\mathrm{Ha}$ diterima dan dapat disimpulkan bahwa penelitian yang telah dilakukan berhasil karena terdapat pengaruh, peneliti menyimpulkan bahwa model pembelajaran Problem Based Learning (PBL) berpengaruh terhadap kemampuan berpikir kritis matematis siswa kelas VIII di SMP Negeri 4 Dewantara. Berdasarkan 
Hal : $12-19$

kesimpulan di atas peneliti memberikan saran yang bermanfaat sebagai berikut: Bagi guru, Model pembelajaran Problem Based Learning (PBL) dapat dijadikan salah satu alternatif dalam pembelajaran matematika pada materi sistem persamaan linear dua variabel. Bagi siswa, diharapkan lebih giat dan aktif lagi dalam pembelajaran. Bagi pembaca, hendaknya skripsi ini dapat menjadi sumber inspirasi penelitian yang lain yang berkaitan dengan Pendidikan, khususnya pembelajaran matematika. Bagi peneliti, hendaknya mampu menerepakan pada materi lain agar menjadi perbandingan dalam meningkatkan kualitas belajar para siswa.

\section{DAFTAR PUSTAKA}

[1] Abda, I.M. 2019. "Penerapan Pendekatan Somatic, Auditory, Visual dan Intellectual (SAVI) Untuk Meningkatkan Kemampuan Komunikasi Matematis dan Disposisi Matematis Siswa Di SMK Negeri 1 Nisam”. Skripsi. Aceh Utara: Universitas Malikussaleh.

[2] Arifin, Z. 2011. Evaluasi Pembelajaran. Bandung. PT. Remaja Rosdakarya.

[3] Arikunto, S. 2013. Prosedur Penelitian: Suatu Pendekatan Praktik. Jakarta: Rineka Cipta.

[4] Arikunto, S. 2017. Prosedur Penelitian: Suatu Pendekatan Praktik. Jakarta: Rineka Cipta.

[5] As'ari, A.R., Tohir, M., Valentino, E., Imron, Z., Taufiq, I. 2017. Buku Paket Matematika SMP/MTs Kelas VIII. Pusat Kurikulum dan Perbukuan, Balitbang, Kemendikbud.

[6] Fatimah, Nurul. 2019. "Pengaruh Model Problem Based Learning Berbantuan Dikotomi Konsep Terhadap Berpikir Kritis ditinjau dari Self Esteem Peserta Didik Kelas X SMA Negeri 15". Skripsi (Internet) (http://repository.radenintan.ac.id) diakses tanggal 30 Juli 2019.

[7] Fisher, A. 2018. Berpikir Kritis. Jakarta: Erlangga

[8] Hendriana, H., Rohaeti, E.E., dan Sumarmo, U. 2017. Hard Skill and Soft Skill Matematika Siswa. Bandung: PT Refika Aditama.

[9] Husnidar, Ikhsan, M, dan Rizal. S. 2014. "Penerapan Model Pembelajaran Berbasis Masalah untuk Meningkatakan kemampuan berpikir Kritis dan Disposisi Matematis Siswa". Jurnal Didaktik Matematika, 1(1), (http://www.jurnal.unsyiah.ac.id) diakses tanggal 25 Juli 2019.

[10] Ibrahim. 2017. "Perpaduan Model Pembelajaran Aktif Konvensional (Ceramah) Dengan Cooperatif (Make-AMatch) Untuk Meningkatkan Hasil Belajar Pendidikan Kewarganegaraan". Jurnal Pendidikan Sosial, Sains, dan Humanion, 3(2): 202. (http://ejournal.uin-suska.ac.id) diakses tanggal 20 September 2020.

[11]Kholida, Diana. 2015. "Pengaruh Problem Based Learning Terhadap Motivasi Belajar Siswa Kelas IX MAN". Skripsi (Internet). (https://lib.unnes.ac.id) diakses tanggal 28 Juli 2019.

[12]Lestari, E.K., Yudhanegara, M.R. 2015. Penelitian Pendidikan Matematika. Bandung. PT. Refika Aditama. Lambertus. 2009. "Pentingnya Melatih Keterampilan Berpikir Kritis dalam Pembelajaran Matematika di SD". Forum Kependidikan, 28(2): 142. (http://forumkependidikan.unsri.ac.id/) ) diakses tanggal 27 Juli 2019.

[13] Normaya, Karim. 2015. "Kemampuan Berpikir Kritis Siswa dalam Pembelajaran Matematika dengan Model Jucuma di Sekolah Menengah Pertama", Jurnal Pendidikan Matematika, 3(1): 92-104. (https://ppjp.ulm.ac.id/) diakses tanggal 06 November 2019.

[14] Nurdyansyah, dan Fahyuni, E. F. 2016. Inovasi Model Pembelajaran. Sidoarjo: Nizama Learning Center.

[15] Nurlaeli, N., Noornia, A., Wiraningsih, E. D. 2018. "Pengaruh Model Pembelajaran Problem Based Learning terhadap Kemampuan Berpikir Kritis Matematis Siswa ditinjau dari Adversity Quotient". Jurnal Pendidikan Matematika, 4(2): 147, (https://jurnal.umj.ac.id/) diakses tanggal 25 Juli2019.

[16] Permendiknas nomor 23 tahun 2006. Standar Kompetensi Kelulusan. (https://disdik.jabarprov.go.id) diakses pada tanggal 27 Januari 2021

[17] Pradana, Y. A., 2016. "Analisa Penyebab Penggunaan Model Konvensional dalam Pembelajaran 
Hal : $12-19$

Bahasa Arab Kelas XI dan XII MAK MAN Wates Kulon Progo". Skripsi (Internet). (http://digilib.uin-suka.ac.id/) diakses tanggal 24 Oktober 2020

[18] Pritasari, A.D.C. 2011. "Upaya Meningkatkan Kemampuan Berpikir Kritis Siswa Kelas XI IPA 2 SMA Negeri 8 Yogyakarta pada Pembelajaran Matematika Melalui pembelajaran Kooperatif Tipe Grup Investigation". Skripsi (Internet). (https://eprints.uny.ac.id/) diakses tanggal 26 Juli 2019.

[19] Rochmah, Miftachur. 2016. "Pengaruh problem Based Learning terhadap Kemampuan Berpikir Kritis Siswa Kelas VIII SMP Muhammadiyah Purworejo". Jurnal Pendidikan Matematika, 22(1): 76-82 (http://ejournal.umpwr.ac.id/)diakses tanggal 28 Juli 2019

[20] Rusman. 2017. Model-model Pembelajaran. Jakarta: Kharisma Putra Utama.

[21] Sari, D. D. 2012. "Penerapan Model Problem Based Learning untuk Meningkatkan Kemampuan Berpikir Kritis Peserta Didik Pada Pembelajaran IPA Kelas VIII SMP Negeri 5 Sleman". Skripsi (Internet). (https://eprints.uny.ac.id/9174) diakses tanggal 30 Juli 2019.

[22] Sianturi,A.,Sipayung,T.N.,danSimorangkir,F.M.A.2018. "Pengaruh Model Pembelajaran Problem Based Learning terhadap Kemampuan Berpikir Kritis Matematis Siswa SMP Negeri 5 Sumbul". Jurnal Pendidikan Matematika, 6(1):29-41(https://jurnal.ustjogja.ac.id/) diakes tanggal 25 Juli 2019

[23] Sugiyono. 2017. Metode penelitian Pendidikan Kuantitatif, Kualitatif, dan R\&D. Bandung: Alfabeta

[24] Yuni, S., Bharata, H., Caswita. 2017. "Pengaruh Problem Based Learning Terhadap Kemampuan Berpikir Kritis Siswa Kelas VIII SMP Negeri 1 Candipuro". Jurnal Pendidikan Matematika, 5(1): 729-736 (http://jurnal.fkip.unila.ac.id/)

[25] Zulyadaini. 2016. "Perbandingan Hasil Belajar Matematika Model Pembelajaran Kooperatif Tipe Coop-Coop Dengan Konvensional". Jurnal IImiah Universitas Batanghari Jambi, 16(1): 153-158 (http://ji.unbari.ac.id/) diakses pada 20 September 2020 